\title{
El trienio antisistema (2015-2017) del nacionalismo catalán
}

\section{The Anti-System Triennium (2015-2017) of Catalan Nationalism}

\author{
David Ortega $^{1}$ \\ Universidad Rey Juan Carlos (España) \\ ORCID: https://orcid.org/0000-0002-8576-8267
}

Recibido: 23-04-2021

Aceptado: 10-05-2021

\section{Resumen}

En el presente artículo se estudian las principales actuaciones de los tres años (2015-2017) del gobierno y el parlamento catalán que culminan con la declaración unilateral de independencia del día 27 de octubre de 2017. Nos centramos principalmente en las siguientes cuestiones: el llamado derecho a decidir; el apoyo (o no) internacional y de la Unión Europea al proyecto secesionista catalán; la (in)viabilidad económica del mismo; la ruptura del marco jurídico, social y democrático en Cataluña y parte de la batalla informativa que ha rodeado al proyecto secesionista.

Palabras-clave: nacionalismo catalán, derecho a decidir, declaración unilateral de independencia, democracia constitucional, políticas antisistema, procés.

\begin{abstract}
This article studies the main actions of the three years (2015-2017) of the Catalan government and parliament that culminated in the unilateral declaration of independence on October 27th, 2017. We mainly focus on the following issues: the so-called right to decide; the international and European Union

\footnotetext{
${ }^{1}$ (david.ortega@urjc.es). Catedrático de Derecho Constitucional de la Universidad Rey Juan Carlos, Vicerrector de Extensión Universitaria de la URJC en los años 2003-2010 y 2017-2021, Premio Nacional de Investigación e Innovación Educativas 1994, autor de Educación, libertad y tolerancia. Vida y pensamiento de Bertrand Russell, Madrid, Biblioteca Nueva /Fundación José Ortega y Gasset, 2003; Derecho a la comunicación. Un análisis jurídico-periodístico, Madrid, $3^{\mathrm{a}}$ edición, Centro de Estudios Ramón Areces/Servicio de Publicaciones de la URJC, 2017; Retos de la libertad de información, Madrid, Dykinson, 2017.
} 
support (or not) for the Catalan secessionist project; their economic viability (or not); the legal, social and democratic framework breakdown in Catalonia and some of the informational battle about the secessionist project.

Keywords: Catalan nationalism, right to decide, unilateral declaration of independence, constitutional democracy, anti-system policies, procés.

\section{Introducción}

Este trabajo de investigación se va a centrar en el análisis de las principales actuaciones del nacionalismo catalán entre los años 2015 y 2017. Estimamos que este periodo temporal es el más relevante para tratar de entender el antes y el después de la declaración unilateral de independencia del parlamento de Cataluña de 27 de octubre de 2017. Estudiaremos algunos de los diferentes acontecimientos que nos llevaron hasta ese momento tan destructivo para nuestra convivencia democrática, para concluir viendo cómo al final de todo el proceso el interés general del pueblo español y de los propios catalanes, el Estado de Derecho y bastantes derechos fundamentales que lo sustentan se han visto seriamente dañados, en un ataque directo a nuestro sistema democrático de convivencia: de ahí la denominación utilizada de dicho trienio como "antisistema". El nobel de literatura Vargas Llosa afirma que los nacionalismos "son incompatibles con la democracia y la libertad", para concluir señalando que "han sido la desgracia de este país" con datos contrastables si el conocido escritor exagera o describe una realidad. Lógicamente, nos centraremos en aquellos que estimamos más relevantes; un estudio más detallado excede los límites de este artículo.

\section{Año 2015: el proyecto rupturista del Presidente Artur Mas}

Entendemos que el año clave de inicio del proyecto rupturista es el $2015^{3}$, aunque, naturalmente, este año es el resultado de un "previo abono" que Fernández-Llebrez González estructura en: a) unos mecanismos ambientales, como el Estatuto de Autonomía catalán de 2006, las elecciones autonómicas de ese mismo año, la crisis económico-financiera y social de 2008, la Sentencia del

\footnotetext{
${ }^{2}$ Ver entrevista al escritor en $A B C$ de 17 de enero de 2021, pp. 12-14: https://www.abc.es/cultura/ abci-entrevista-vargas-1losa-ley-celaa-disparate-absoluto-202101170059 video.html

${ }^{3}$ Como reconocen Steven Forti, Arnau González i Vilalta y Enric Ucelay-Da Cal en las conclusiones de su libro: "Las elecciones del 27 de septiembre de 2015 [...] ya era el Procés, recién denominado para dar sentido a todo lo que sucedía". Ver de los autores citados, El Proceso separatista en Cataluña. Análisis de un pasado reciente (2006-2017), Granada, Comares, 2017, p. 293.
} 
Tribunal Constitucional 31/2010, de 28 de junio, que declara inconstitucionales bastantes artículos del Estatuto de 2006, y la victoria por mayoría absoluta del PP en las elecciones generales de 2011; b) unos mecanismos cognitivos que se concretan en el nacimiento de la Asamblea Nacional Catalana (ANC) el 10 de marzo de 2012. Respecto de la misma, Rodríguez Mesa ${ }^{4}$ estima que es determinante en el cambio de discurso del nacionalismo, incluso por encima de la Asociación de Municipios por la Independencia (AMI) ${ }^{5}$, que nace tres meses antes; y, por último, c) unos mecanismos relacionales, centrados en el giro político de $\mathrm{CiU}^{6}$.

Por lo demás, es poco discutible que desde el año 2006 del Estatut hasta el año 2015 de inicio del Procés, la opción independentista pasa en Cataluña de no superar el 20\% a estabilizarse a partir de 2012 en más del 40\%, según las encuestas del Instituto de Ciencias Políticas y Sociales (ICPS) ${ }^{7}$. En esta misma línea de apuntar un cambio social y político en el año $2012^{8}$, hay que recordar, como señala el profesor Andrew Dowling, que la Diada de 2012 "fue el momento en que el control pasó de las instituciones políticas a la calle [...] esta lucha por el control del movimiento no se completó hasta que la candidatura unitaria de Junts pel Sí incorporó la ANC y Òmnium Cultural como partícipes directos en la lista electoral ante los comicios catalanes del 27 de septiembre de 2015". Igualmente se posiciona Cano Paños, al afirmar que "el 11 de septiembre del año 2012 se produjo en Cataluña la primera gran manifestación en favor de la independencia, aprovechando para ello la celebración de la Diada. Dicha manifestación reivindicativa fue organizada, entre otras, por dos asociaciones civiles que, años más tarde, tendrían un protagonismo destacado en el intento secesionista catalán: Òmnium Cultural y la Associació Nacional de Catalunya"10.

El 14 de enero de 2015 los dos principales partidos independentistas CiU y ERC- acuerdan celebrar un referéndum "de facto" a través de las

${ }^{4}$ Ver Cristian Rodríguez Mesa, "Discurso y prácticas políticas del catalanismo: Del nacionalismo al independentismo instrumental" en Steven Forti, Arnau González i Vilalta y Enric Ucelay-Da Cal (eds.), El Proceso separatista en Cataluña... ob. cit., pp. 38-39.

${ }_{5}$ Nace el 14 de diciembre de 2011. En 2017 abarcaba 787 municipios de los 948 de Cataluña.

${ }^{6}$ Ver Fernando Fernández-Llebrez González, "Mecanismos ambientales, cognitivos y relacionales en el surgimiento del actual movimiento independentista catalán”, en Revista de Estudios Regionales, $\mathrm{n}^{\mathrm{o}} 117,2020$, p. 116 .

7 Ctdo. en Steven Forti, Arnau González i Vilalta y Enric Ucelay-Da Cal (eds.), El Proceso separatista en Cataluña... ob. cit., pp. 120-121, gráfico 3. Preferencia por la independencia.

${ }^{8}$ Ignacio Sánchez-Cuenca también sitúa el inicio de la crisis catalana en el año 2012, ver del autor, La confusión nacional. La democracia española ante la crisis catalana, Madrid, Catarata, 2018, p. 13.

9 Ver Andrew Dowling, "La calle como plataforma de comunicación. De la Crida a la Assemblea Nacional Catalana" en Steven Forti, Arnau González i Vilalta y Enric Ucelay-Da Cal El Proceso separatista en Cataluña..., ob. cit., p. 185.

${ }^{10}$ Ver Miguel Ángel Cano Paños, "Los delitos de rebelión y sedición en el ordenamiento jurídico español y su eventual aplicación al proceso independentista catalán" en Revista electrónica de Estudios Penales y de la Seguridad, no 5, 2019, p. 4. También en www.ejc-reeps.com

Araucaria. Revista Iberoamericana de Filosofia, Política, Humanidades y Relaciones Internacionales, año $23, \mathrm{n}^{\circ} 47$. Segundo cuatrimestre de 2021. Pp. 315-339. ISSN 1575-6823 e-ISSN 2340-2199 https://dx.doi.org/10.12795/araucaria.2021.i47.15 
elecciones autonómicas anticipadas del 27 de septiembre de 2015. La doctrina constitucional, respecto del carácter plebiscitario de estas elecciones, tiene una postura claramente contraria. Blanco Valdés se remite, para determinar el objeto de las mismas, a lo que determine "el decreto de convocatoria. Por tanto no hay elecciones plebiscitarias ni hay más plebiscitos que los que son legalmente convocados como tales" pretende encubrir una toma de decisión no explícita en el marco de la secesión de Cataluña del resto de España" ${ }^{2}$. García Fernández directamente habla de "otra falacia de las tantas que ha elaborado, con dinero público, el aparato de propaganda y agitación de los independentistas"13. Por último, Montilla Martos, en una línea similar, lo describe como "un mero artilugio retórico sin mayor alcance, $[\ldots]$ construcciones dogmáticas sin sustento constitucional"14.

La participación de las elecciones del $27 \mathrm{~S}$ fue realmente elevada, el $77,44 \%$. La formación denominada Junts pel Sí (fruto de la coalición entre Convergencia y Esquerra) obtuvo 62 de los 135 escaños totales, mientras que la CUP consiguió 10. Por lo tanto, el independentismo tenía asegurada la mayoría absoluta del Parlamento, aunque es verdad que entre ambas formaciones no superaron el 50\% de los votos (se quedaron en el 47,8 \%). Sin embargo, la lectura realizada por el Presidente Mas fue, como declaró, que "estamos legitimados para seguir adelante". Evidentemente, este seguir adelante no es otro objetivo que la declaración unilateral de independencia de Cataluña, que comparten las tres fuerzas independentistas citadas.

\subsection{Diez errores del proyecto secesionista}

Un primer análisis, dentro de aquel contexto, que ya se podía deducir claramente en el propio año 2015, era el siguiente decálogo en contra de un viaje a ninguna parte, como el tiempo ya ha demostrado. Se podían apuntar ya entonces al menos diez razones para rechazar radicalmente el planteamiento político del Presidente Artur Mas y del resto de fuerzas políticas que lo apoyaban, principalmente por su carácter inviable o falta de contacto con la realidad.

1. El aislamiento internacional del proyecto de Mas era más que significativo. Tenía el rechazo de la principal potencia del planeta, los Estados Unidos de Norteamérica. El Presidente Obama expresamente apostaba por una España fuerte y unificada. Igualmente sucedía con la principal potencia europea: Merkel también se manifestó en el mismo sentido. El independentismo catalán no quería

11 Ver Teoría y Realidad Constitucional, $\mathrm{n}^{\circ} 37.1^{\circ}$ semestre 2016, monográfico "La cuestión catalana", p. 49.

12 Ibidem, p. 55. Para concluir afirmando que "todo el denominado 'procés' ha estado jalonado de tergiversaciones de las instituciones jurídicas, retorciendo los conceptos jurídicos básicos de las democracias actuales".

${ }^{13}$ Ibidem, p. 57.

${ }^{14}$ Ibidem, p. 58.

Araucaria. Revista Iberoamericana de Filosofia, Política, Humanidades y Relaciones Internacionales, año $23, \mathrm{n}^{\circ} 47$. Segundo cuatrimestre de 2021. Pp. 315-339. ISSN 1575-6823 e-ISSN 2340-2199 https://dx.doi.org/10.12795/araucaria.2021.i47.15 
asumir su aislamiento internacional. Este error de cálculo grave se constató en octubre de 2017: ningún país respaldó la declaración de independencia del 27 de octubre de 2017. A la Europa moderna del siglo XXI no le gustan los nacionalismos y, además, y este es el gran error del nacionalismo catalán, el camino elegido, un proceso de secesión unilateral, "es abiertamente contrario tanto a las normas de derecho positivo como a la práctica desarrollada por los Estados"15, y de ahí, lógicamente, la soledad internacional experimentada ${ }^{16}$.

2. Otro argumento complementario del anterior es que Europa no permite la desintegración de los Estados. Los tiempos históricos son justo lo contrario. Se va hacia la Unión, no hacia la desintegración o atomización. Una futura Cataluña no tendría cabida en Europa, sería un elemento extraño, distorsionador $\mathrm{y}$ un mal e inquietante precedente, por nadie querido ${ }^{17}$.

3. Viabilidad económica del proyecto. No parece que los líderes independentistas se platearan con rigor sobrevivir económicamente al margen de Europa y sus mercados, del propio mercado español, de las ayudas de la Unión Europea, de las importantes editoriales en español que hay en Cataluña, de cómo reaccionaría el resto de España ante las entidades financieras catalanas y resto de empresas. Está demostrado que Cataluña funciona dentro de España, no lo contrario, y el error puede ser dramático. Nuevamente la realidad posterior a 2015 lo demostró. Miles de empresas, más de $7.000^{18}$, han abandonado Cataluña después del 27 de octubre de 2017. José Luis Leal, al estudiar el coste de la independencia a nivel económico, apunta como lo más perjudicial la aplicación de la tarifa aduanera exterior común, que encarecería las exportaciones catalanas a la Unión Europea entre un 3\% y un 5\%. Para poder competir, salarios y beneficios retrocederían en unos dos puntos porcentuales del PIB. Se perderían las ayudas del Banco Central Europeo y destacaría, sobre todo, el problema de la deuda, que en Cataluña asciende a 76.700 millones de euros y en materia de pensiones el déficit es de 6.700 millones de euros al año ${ }^{19}$. Para un estudio más detallado está la obra de Josep Borrell y Joan Llorach, Las cuentas y los cuentos de la independencia ${ }^{20}$.

\footnotetext{
15 Ver Rafael Calduch Cervera, "El fracaso internacional del independentismo catalán: causas jurídicas y políticas” en Anuario Español de Derecho Internacional, 2019, vol. 35, p. 131.

16 Ibídem, p. 147: "La negativa de los gobiernos de las principales potencias, Estados Unidos; Rusia; Francia, Alemania o Reino Unido, a aceptar la legalidad del referéndum del 1 de octubre de 2017 y la DUI, constituyó un decisivo revés internacional para la viabilidad del proyecto secesionista".

17 Ver Carlos Fernández de Casadevante, "El proyecto independentista catalán a la luz del Derecho Internacional y de la Unión Europea” en Cataluña en claro, ed. FAES, 2014, pp. 83-98.

${ }^{18}$ En febrero del año 2021 se aproximan a 7.000 las empresas que han abandonado Cataluña, según la prensa económica especializada, ver:

https://www.eleconomista.es/economia/noticias/11045875/02/21/Cataluna-supera-las-7000empresas-huidas-desde-el-principio-del-proces.html

${ }_{19}$ Ver José Luis Leal, el coste de la independencia, el País de los Negocios 5 de noviembre de 2017: https://elpais.com/economia/2017/11/02/actualidad/1509638840 783543.html

${ }^{20}$ Ver Josep Borell y Joan Llorach, Las cuentas y los cuentos de la independencia, Madrid, ed. Los libros de la catarata, 2015.
} 
4. No hay democracia sin Estado de Derecho. Éste constituye un principio esencial de los Estados democráticos, algo que el independentismo catalán no quiere admitir, ni asumir. "Nos damos leyes para no darnos tiranos", se decía durante la Revolución Francesa. Nadie está por encima de la norma, que todos tenemos que respetar. En este sentido, el planteamiento de Mas y compañía hace agua por todas partes y se aproxima al gamberrismo; otros hablan de golpismo político. La consulta no es viable en términos de derecho a decidir, pues la norma superior que todos nos hemos dado, la Constitución Española, es muy clara al respecto en su artículo 1.2: "la soberanía nacional reside en el pueblo español del que emanan todos los poderes del Estado". España, sus tierras, sus fronteras, su población, solo tiene un único titular: los 47 millones de españoles en su conjunto. A todos, absolutamente a todos, nos pertenecen Galicia, Andalucía, Cataluña o el Principado de Asturias. Todos somos titulares de esos bienes. No podemos, ni debemos permitir que unilateralmente una parte decida o pueda decidir quitárnoslos. Todo español tiene derecho a seguir yendo a Cataluña como nación propia, no extraña, sin aceptar que nadie quiera decidir quitársela, básicamente porque no tiene ningún título que le legitime para ello. Entiendo que éste es el argumento más decisivo: Cataluña, Castilla y León o Extremadura son territorios, todos ellos como conjunto, que pertenecen a todos los españoles.

5. Para mayor claridad, si cabe, el artículo 2 proclama "la indisoluble unidad de la Nación española, patria común e indivisible de todos los españoles". Es el complemento lógico al artículo 1.2: las tierras pertenecen al soberano, que es el pueblo español. El Estado español tiene tres elementos claves, como cualquier Estado: su territorio, su población y su gobierno y todo ello pretenden Mas y compañía tener el derecho a decidir cambiarlo. Ese derecho, lógicamente no existe, como veremos en detalle más adelante ${ }^{21}$.

6. El Presidente Mas se ha auto-constituido en poder constituyente, cuando solo es poder constituido. Esto no es un juego de palabras, es una brutalidad jurídica por no respetar lo básico y esencial de los Estados serios y democráticos. El secesionismo catalán se quiere situar fuera o por encima de la Constitución, como nuevo poder constituyente. Lo trágico de la cuestión es que el Presidente Mas es poder constituido ${ }^{22}$ precisamente fruto de la Constitución a la que ataca, su autonomía existe gracias a ella, el gobierno de la Generalidad es resultado del Título VIII de la Constitución.

7. Los españoles deben recordar que hemos tardado dos siglos en lograr que España funcione como un país moderno y democrático, que por el camino hemos dejado mucha lucha, sacrificios y fracasos. La Constitución de 1978

${ }^{21}$ Infra, apartado 2.2. El derecho a decidir: ¿un derecho democrático o una falacia informativa?

${ }^{22}$ Más adelante desarrollamos esta idea esencial y diferencial entre el poder constituyente/poder constituido.

Araucaria. Revista Iberoamericana de Filosofia, Política, Humanidades y Relaciones Internacionales, año $23, \mathrm{n}^{\circ} 47$. Segundo cuatrimestre de 2021. Pp. 315-339. ISSN 1575-6823 e-ISSN 2340-2199 https://dx.doi.org/10.12795/araucaria.2021.i47.15 
es nuestro gran éxito de convivencia después de ocho textos constitucionales fracasados, tres guerras civiles en el siglo XIX y una terrible en el XX, dos dictaduras y varios golpes militares. No debemos olvidar, para no volver, a la indeseable inestabilidad constitucional y política de nuestro peor pasado.

8. Hay una cierta clase política catalana -los independentistas- que obvian el perjuicio que su proyecto genera al resto de los españoles. Se creó un Estado Autonómico para dar cabida principalmente a sus deseos, para tratar de integrar y poder convivir con los nacionalismos catalán y vasco. Pues bien, frente a ese pacto o acuerdo de convivencia se utilizan las instituciones y los procedimientos intrínsecos a ellas para hacer justo lo contrario: romper la convivencia y la propia Norma Fundamental que la genera.

9. Hace muchos años que Habermas nos advirtió de los peligros que acechan a la democracia cuando en la política desaparecen los argumentos racionales y jurídicos, y entran en juego los elementos emocionales o sentimentales ${ }^{23}$. La democracia representativa y el Estado contemporáneo son fruto precisamente de la racionalización y normativización, en importante medida, del actuar político. Es una de las principales aportaciones de las revoluciones liberales del XVIII, en base a tres pilares esenciales: la separación de poderes, el principio de legalidad y la declaración de derechos. Sólo los defensores del antiguo régimen se basaban en la historia, en el pasado, en los sentimientos. Ya a mediados del pasado siglo García-Pelayo dejo claro que el único concepto de constitución válido y democrático es el racional-normativo, frente al histórico y al sociológico ${ }^{24}$. La democracia tiene su base en la norma y en el racionalismo jurídico y, muy especialmente, de la mano de Jean Jacques Rousseau y su Contrato Social, del bien común, de la voluntad general expresada en la norma de convivencia, esto es, la Constitución. Sin embargo, el historicismo siempre miró con recelo el nuevo Estado democrático y constitucional.

10. En política hay que defender el interés general, el bien común, lo que beneficia al mayor número. España y Cataluña se necesitan como proyecto común. La historia demuestra que la suma es mejor que la resta, la unión que la desintegración, la convivencia que el enfrentamiento. Jacques Pirenne lo expresa con claridad en el inicio de su Historia Universal, debemos tener grandeza y perspectiva histórica: "Los periodos ascendentes de la civilización son aquellos que ensanchan los cuadros de la comunidad humana, creando una solidaridad material y moral entre un número cada vez mayor de pueblos [...] Los periodos de decadencia son aquellos en que las grandes comunidades se disgregan, en que la sociedad, cual cuerpo muerto, se descompone y disuelve" 25 .

\footnotetext{
${ }^{23}$ Ver la excelente monografía de Evaristo Prieto Navarro, Jürgen Habermas, acción comunicativa e identidad política, Madrid, Centro de Estudios Políticos y Constitucionales, 2003.

${ }^{24}$ Ver Manuel García-Pelayo, Derecho constitucional comparado, Madrid, Alianza, 1999.

${ }_{25}$ Ver Jacques Pirenne, Historia Universal. Las grandes corrientes de la historia, vol. I, Barcelona, ediciones LEO, 1953, p. XI.
} 


\subsection{El derecho a decidir: ¿un derecho democrático o una falacia comunicativa?}

En pocos asuntos la doctrina constitucional es tan mayoritaria, por no decir prácticamente unánime, al declarar la inexistencia del tan mentado por los nacionalistas catalanes "derecho a decidir". Apuntemos las fuentes.

La revista Teoría y Realidad Constitucional publica en el primer semestre de 2016 un número monográfico sobre "la cuestión catalana"26. Como en otros monográficos, se abre con una encuesta, en esta ocasión, a ocho catedráticos de derecho constitucional; de ellos, tres de universidades catalanas y uno del País $\operatorname{Vasco}^{27}$. La pregunta $\mathrm{n}^{\mathrm{O}} 4$ de la encuesta dice así: “¿Qué valoración técnicojurídica le merece el llamado derecho a decidir?"

Es clarificador que los ocho encuestados coinciden en su respuesta. Enoch Albertí Rovira apunta que el "llamado derecho a decidir [...] no existe hoy en términos estrictamente jurídicos" 28 . Roberto Blanco Valdés indica que "ese pretendido derecho a decidir sencillamente no existe, no está reconocido en ninguna Constitución democrática del mundo, pues ningún Estado regula el proceso de su propia destrucción" 29 . Enric Fossas Espadaler señala, de manera parecida, que el "llamado derecho a decidir es uno de los eufemismos en los que se ha basado el proceso catalán" ${ }^{30}$. Teresa Freixes Sanjuan, en una postura similar a la del profesor Blanco, sostiene que "el denominado derecho a decidir, mal que les pese a quienes lo defienden, jurídicamente no existe. Ningún texto jurídico, nacional, europeo o internacional, lo reconoce ni regula" ${ }^{\text {31 }}$. Javier García Fernández recurre a la jurisprudencia del Tribunal Constitucional para mantener la misma idea. Así, nos recuerda que "la noción de "derecho a decidir" es ajena al ordenamiento español, como se infiere de la Sentencia constitucional 103/2008, de 11 de septiembre, que declaró inconstitucional la Ley vasca que pretendía conceder a los ciudadanos de esa Comunidad Autónoma el derecho a decidir"32. José Antonio Montilla Martos aclara los equívocos con el sí existente derecho de

26 Ver Teoría y Realidad Constitucional, monográfico, "la cuestión catalana", n 37, 1. semestre 2016, Madrid, UNED, 626 páginas. Más extensamente sobre el derecho a decidir, ver Eduard Sagarra Trías (coord.), ¿Existe el derecho a decidir? Preguntas y respuestas sobre el proceso abierto en Cataluña, Tibidabo, Barcelona, 2014; VV.AA., El derecho a decidir. Teoría y práctica de un nuevo derecho, Atelier, Barcelona, 2015 y Xavier Pons Rafols, Cataluña: Derecho a decidir y derecho internacional, Reus, Madrid, 2015.

${ }^{27}$ Concretamente Enoch Albertí Rovira, Universidad de Barcelona; Roberto L. Blanco Valdés, Universidad de Santiago de Compostela; Enric Fossas Espadaler, Universidad Autónoma de Barcelona; Teresa Freixes Sanjuan, también de la UAB; Javier García Fernández, UCM, José Antonio Montilla Martos, Universidad de Granada; Miguel Satrústegui Gil-Delgado, Profesor Titular de la UC3M y Eduardo Virgala Foruria, Universidad del País Vasco.

${ }^{28}$ Ver Teoría y Realidad Constitucional, monográfico, "la cuestión catalana” ..., ob. cit., p. 45.

${ }^{29}$ Ibidem, p. 47.

${ }^{30}$ Ibidem, p. 49.

31 Ibidem, p. 51.

32 Ibidem, p. 56.

Araucaria. Revista Iberoamericana de Filosofía, Politica, Humanidades y Relaciones Internacionales, año $23, \mathrm{n}^{\circ} 47$. Segundo cuatrimestre de 2021. Pp. 315-339. ISSN 1575-6823 e-ISSN 2340-2199 https://dx.doi.org/10.12795/araucaria.2021.i47.15 
autodeterminación. Dice así: "El derecho a decidir es un eufemismo para referirse al derecho de autodeterminación. Dado que el derecho de autodeterminación tiene unos rasgos definitorios en Derecho Internacional que no son aplicables al caso de Cataluña al no tratarse de una colonia ni estar sometido a una potencia extrajera se pretende sustituir por el derecho a decidir"33. Miguel Satrústegui GilDelgado afirma que "jurídicamente se trata de una proposición ineficaz, porque los derechos dependen del ordenamiento, no de postulados ideológicos. Y ni la Constitución española (que en esto se asemeja a las de los demás Estados occidentales) ni el Derecho internacional contemplan un derecho colectivo semejante"34. Por último, Eduardo Virgala Foruria, como el profesor Montilla, lo diferencia del derecho de autodeterminación y añade en la distinción el derecho de secesión: "jurídicamente no existe el derecho a decidir ni desde el punto de vista del derecho de autodeterminación ni del derecho de secesión" 35 .

Colateralmente, en los fundamentos para negar la existencia del derecho a decidir, algunos de los profesores mentados han traído a colación el derecho de autodeterminación y el derecho de secesión. Merece la pena aclarar estas dos diferencias, para despejar posibles dudas y mantener un análisis riguroso en términos jurídicos.

Parece poco discutible que el tan utilizado derecho a decidir, argumento esencial del nacionalismo catalán, simplemente no existe. Sí existe en cambio en el ámbito del derecho internacional el denominado derecho de autodeterminación. Diferentes Resoluciones de Naciones Unidas han tratado esta materia. Normalmente se atiende a dos $^{36}$ : la Resolución 1514 (XV) de las Naciones Unidas de 14 de diciembre de 1960, conocida como la Carta Magna de la Descolonización y la Resolución 2625 (XXV) de 24 de octubre de 1970, Declaración relativa a los principios de Derecho internacional referentes a las relaciones de amistad y a la cooperación entre los Estados de conformidad con la carta de Naciones Unidas. A la luz de las mismas, solo en tres casos se reconoce el derecho de autodeterminación: "pueblos colonizados, pueblos ocupados militarmente y pueblos en los que hay una clara vulneración de los derechos humanos"37. Como sostiene Virgala Foruria: "en ningún caso se dan en Cataluña las características exigidas por Naciones Unidas"38. La cuestión resulta pues

${ }^{33}$ Ibidem, p. 57.

${ }^{34}$ Ibídem, p. 58.

${ }^{35}$ Ibidem, p. 60.

${ }^{36}$ Con menor frecuencia, pero también se cita la Resolución 1541 (XV) de 15 de diciembre de 1960.

${ }^{37}$ Ver Fernando Carrera, Fernando Roca y Pedro Pérez-Cuesta, Las mentiras del independentismo catalán, Madrid, ed. BuenasLetras, 2017, p. 19.

${ }^{38}$ Ver Teoría y Realidad Constitucional, monográfico, "la cuestión catalana" ..., ob. cit., p. 60. En la misma línea, Calduch Cervera: "la realidad política y jurídica de la Comunidad Autónoma de Cataluña y de sus ciudadanos, no responde a las circunstancias de un pueblo sometido a una dominación colonial ni tampoco a las de un territorio no autónomo", además, "el pueblo catalán ha podido ejercer el derecho a expresar su libre voluntad política (autodeterminación) respecto de

Araucaria. Revista Iberoamericana de Filosofia, Política, Humanidades y Relaciones Internacionales, año $23, \mathrm{n}^{\circ} 47$. Segundo cuatrimestre de 2021. Pp. 315-339. ISSN 1575-6823 e-ISSN 2340-2199 https://dx.doi.org/10.12795/araucaria.2021.i47.15 
bastante clara, como defiende Calduch Cervera: "atendiendo a los documentos fundamentales del denominado derecho de la descolonización, el principio de la libre determinación de los pueblos no podía aplicarse de una forma expansiva hasta el punto de amparar procesos secesionistas unilaterales" ${ }^{\prime 39}$.

Por lo tanto, el derecho a decidir no existe y el derecho de autodeterminación no es de aplicación. Si de esta última afirmación cupiera alguna duda, la propia citada Resolución 2625 nos la despeja: "Ninguna de las disposiciones de los párrafos precedentes se entenderá en el sentido de que autoriza o fomenta cualquier acción encaminada a quebrantar o menospreciar, total o parcialmente, la integridad territorial de Estados soberanos e independientes que conduzcan de conformidad con el principio de igualdad de derechos y de libre determinación de los pueblos antes descritos y estén, por tanto dotados de un gobierno que represente a la totalidad del pueblo perteneciente al territorio, sin distinción por motivo de raza, credo o color" $"$.

En cuanto al derecho de secesión, esto es, el derecho de una parte del territorio de un Estado a separarse del resto de ese Estado, no está reconocido en la Constitución Española. Es un derecho muy poco reconocido en el derecho constitucional, tanto histórico como comparado, pues es extraño que un Estado contemple su propio desmembramiento. Actualmente, solo se da en las Constituciones de "St. Kitt y Nevis ${ }^{41}$, Etiopia y Uzbekistán" ${ }^{42}$. Vergottini ${ }^{43}$ señala, además de Uzbekistán, la Constitución de 1921 del Principado de Liechtenstein y la de Sudán de 2005. En total tenemos, por lo tanto, cinco países. Por último, como sostiene Fernández de Casadevante Mayordomo, "en el derecho constitucional comparado [...] la secesión unilateral, por vía de los hechos, es siempre contraria a derecho. A partir de ahí, son distintos los planteamientos defendidos en relación con la posibilidad de reformar la Constitución de cara a incluir en ella una cláusula de secesión" ${ }^{\prime 4}$.

la Constitución de 1978 y del Estatuto de Autonomía". Ver Rafael Calduch Cervera, "El fracaso internacional del independentismo catalán..., ob. cit., p. 132.

${ }^{39}$ Ibídem, p. 134.

40 Incluido en el apartado dedicado a "El principio de la igualdad de derechos y de la libre determinación de los pueblos", penúltimo párrafo, ver https://www.dipublico.org/3971/ resolucion-2625-xxv-de-la-asamblea-general-de-naciones-unidas-de-24-de-octubre-de-1970que-contiene-la-declaracion-relativa-a-los-principios-de-derecho-internacional-referentes-alas-relaciones-de/

${ }^{41}$ Conocido también por San Cristóbal y Nieves.

${ }^{42}$ Ver Teoría y Realidad Constitucional, monográfico, "la cuestión catalana"..., ob. cit., p. 61.

${ }^{43}$ Ver Giuseppe de Vergottini, "Referéndum y secesión" en Teoría y realidad constitucional, $\mathrm{n}^{\circ}$ 43, 2019, p. 109.

${ }_{44}$ Ver Pablo Fernández de Casadevante Mayordomo, "La secesión vía reforma constitucional en el derecho comparado" en Carlos Fernández de Casadevante Romani (dtor.), Consecuencias jurídicas de la secesión de entidades territoriales. Una visión para España, Cizur Menor, Aranzadi, 2020, p. 96. 


\subsection{La batalla informativa: información versus manipulación}

En sí misma, esta materia requeriría una tesis doctoral bastante extensa para poder abordarla con el rigor y la seriedad que merece. Nos hemos limitado en este punto, tomando por base distintos trabajos, a extraer algunas conclusiones de los mismos que nos parecen de interés.

En principio, parece que el nacionalismo catalán ha apostado más fuertemente por ganar la batalla comunicativa, dedicando más medios y esfuerzos que los defensores de la postura constitucionalista. Así se desprende del estudio de Gil Ramírez, especialmente en el caso de YouTube: "Para concluir, y tratando de responder al objetivo genérico de presentar, mediante este análisis, una visión general sobre la polarización política generada en nuestro país con la cuestión de la Independencia de Cataluña, cabe constatar que el polo soberanista tiene mayor peso (tanto en temáticas, como en número de vídeos publicados) que el polo constitucionalista. Es decir, el prosumidor, tanto como productor como consumidor ha estado más interesado por los hechos (insólitos en la historia de la política española) generados desde el entonces Govern catalán, que por las medidas adoptadas ante estos hechos por el Gobierno Español. Igualmente, en el entorno de YouTube, han generado mayor expectación las manifestaciones ciudadanas del lado independentista que aquellas a favor de la unidad de España"45.

No parece que esta línea cambie en el caso de Instagram. Podemos afirmar que, en las redes, según los estudios consultados, el independentismo ha tenido más presencia. Así se desprende del trabajo de Cartes Barroso: "En resumen, en líneas generales podemos concluir afirmando que los partidos independentistas -verdaderos artífices del referéndum-, son las formaciones que más apuestan por Instagram durante el periodo analizado, si bien deben mejorar su estrategia y aprovechar todas las utilidades de esta red social, al igual que los partidos no independentistas" $"$.

Igualmente pasa con Twitter, los soberanistas han estado por delante de los defensores del sistema constitucional de 1978, siendo más influyentes las asociaciones ciudadanas independentistas que las constitucionalistas: "al menos en lo que respecta a la 'campaña' del referéndum del 1 de octubre de 2017 en Cataluña vivida en la red social Twitter, las entidades sociales, y en concreto las partidarias de la independencia, han sido las más efectivas en la gestión de la comunicación"47.

${ }^{45}$ Ver Marta Gil Ramírez, "El uso de YouTube en el Procés catalán. Comunicación política a través de los social media: ¿prosumidores mediatiados?” en Estudios sobre el mensaje periodístico, Ediciones Complutense, no 25 (1) 2019, p. 231.

46 Ver Manuel Jesús Cartes Barroso, "El uso de Instagram por los partidos políticos catalanes durante el referéndum del 1 - 0" en Revista de Comunicación de la SEECI, n 47, 15 noviembre 201815 marzo 2019, p. 33-34.

47 Ver Rafael Carrasco Polaino, Ernesto Villar Cirujano y Laura Tejedor Fuentes, "Twitter como 
En las principales agencias internacionales informativas también se mantiene la presencia favorable a las posturas independentistas, según el estudio de Carlos López-Olano y Vicente Fenoll: "En RT (Russia Today), los posts que utilizan una cobertura más próxima a las posiciones independentistas reciben un mayor número de reacciones positivas, como me asombra y me divierte. Especialmente, durante la retransmisión en directo de las protestas y manifestaciones en Barcelona tras la detención de Puigdemont. También en DW (Deutsche Welle) encontramos una asociación, aunque más moderada, entre el sesgo del post y la reacción de los usuarios: los posts más favorables al independentismo reciben un mayor número de reacciones positivas, como me gusta, me divierte y me encanta. En el caso de la corporación alemana, esta tendencia aparece con más fuerza en los posts desfavorables al constitucionalismo, sobre todo cuando se informa sobre el rechazo de la justicia alemana a entregar a Puigdemont a España. La corporación británica, BBC, es la que menor espacio dedica a la cobertura del conflicto catalán, con una posición ligeramente más cercana al constitucionalismo, que no genera ningún tipo de interacción significativa en los usuarios. En definitiva, los datos analizados comprueban la importancia en la agenda de las noticias sobre el conflicto independentista en RT, constatan la ligera coloración en el sesgo de esta corporación, y la diferencia significativa en comparación con el período álgido del 1-O, obtenido en los análisis en trabajos previos. Esto ubicaría a RT en comparación con sus homólogos en una situación de cadena moderada, pero cercana aun así a las campañas de desestabilización de los medios rusos pro-Putin, denunciadas por diversos autores citados en el texto" ${ }^{\prime 4}$.

El tema de las fake news en el Procés también han suscitado algún estudio de interés. La Universidad de Sevilla ha sido bastante activa en esta materia y algún trabajo fin de grado (TFG) se ha centrado en esta cuestión. Las principales conclusiones a que el mismo llega, verifican la constatación de bastantes fake news usadas en este caso, según datos del estudio, por los defensores del independentismo. Así, apunta que "en primer lugar es necesario recordar cuál es la hipótesis principal de este estudio: que el 1 de octubre de 2017 circularon noticias falsas en Twitter que contribuyeron a desinformar a la población. Tras finalizar el estudio y el análisis de las fake news más destacadas del 1-O podemos decir que nuestra hipótesis principal se confirma. Nos hemos encontrado con un total de 24 noticias que fueron difundidas por cientos de personas y, en otros casos, por miles de personas que las creyeron como ciertas.

herramienta de comunicación política en el contexto del referéndum independentista catalán: asociaciones ciudadanas frente a instituciones públicas" en Icono 14, enero-junio 2018, vol. 16, n ${ }^{\circ}$ 1, p. 83.

${ }_{48}$ Ver Carlos López-Olano y Vicente Fenoll, "La polarización mediática en el proceso de independencia en Cataluña. Estudio comparativo del tratamiento en RT" en Revista Mediterránea de Comunicación, $\mathrm{n}^{\circ} 11$ (1), 2020, pp. 269-270. 
La mayoría de los tweets no fueron rectificados por su autor, por lo que hoy en día siguen 77 circulando en Twitter. Sólo un 48\% de las fake news fueron desmentidas por otros medios o por otros usuarios. En esta línea y en relación con la segunda hipótesis de la investigación es la intervención de la política en la difusión de estas noticias falsas. Tras analizarlas, podemos observar que no solo fueron difundidas por ciudadanos anónimos, sino que importantes periodistas y figuras representativas del independentismo en el panorama político hicieron uso de ellas en sus cuentas oficiales. Periodistas internacionales con miles de seguidores han sido partícipes de esta desinformación, esta perspectiva nos lleva a cuestionarnos el papel del periodismo"49.

Hay otro TFG también de la Universidad de Sevilla que aborda si cabe un tema más curioso y de importante repercusión internacional. Así, la investigación se centra en la posible influencia de la Rusia de Putin en el conflicto catalán estudiando principalmente el diario El País, además de otras agencias internacionales influyentes. La conclusión tiene sin duda interés:

"no solo El País se hace eco del asunto, sino que la injerencia rusa en Cataluña cobra un protagonismo internacional y otros medios, como los propios rusos RT o Sputnik $k^{50}$, también hablan de ello. Esta gran difusión de la situación se debe, tal como apuntaba en una de las hipótesis, a que Internet es una herramienta fácil y eficaz, en términos de difusión y de desinformación. En conclusión, creo haber cumplido los objetivos planteados en un primer momento, así como haber respondido a las preguntas planteadas en un inicio. En primer lugar, he investigado y explicado la evolución ideológica de El País, sin llegar a ninguna afirmación absoluta pues el periódico sigue siendo cambiante y no he abarcado todos los matices que habría que tener en cuenta para ello, sobre todo porque esa investigación se desvincula del objeto del trabajo. Además, he analizado la cobertura informativa y explicado el posible origen de la injerencia rusa y su influencia a partir del análisis de las noticias. Por último, en grandes rasgos, he entendido el último objetivo: esta injerencia rusa ha actuado en España con un fin de desprestigiar a la Unión Europea mediante la propaganda y la confusión. Putin en Cataluña, como también en Estados Unidos o en Gran Bretaña. Putin, entendiendo no solo su persona sino el país ruso y su maquinaria propagandística, aprovechando toda oportunidad que permita debilitar la imagen democrática y unitaria de cualquier país de la Unión Europea o contrario a los intereses rusos" $"$.

49 Ver Almudena Delgado Balongo, "El fenómeno de la desinformación en twitter: las fake news del 1-O sobre el conflicto catalán”, TFG dirigido por la doctora Irene Tenorio Vázquez, 2018-2019, grado de periodismo, Facultad de Comunicación, Universidad de Sevilla, pp. 76-77.

${ }^{50}$ Agencia de noticias vinculada al Gobierno ruso nacida en el año 2014.

${ }^{51}$ Ver Concha García Varela, "Putin en Cataluña. La cobertura del diario El País sobre la injerencia rusa en el conflicto catalán (del 1 de octubre hasta el 21 de diciembre de 2017)", TFG dirigido por Juan Carlos Fernández Serrato, 2018-2019, grado de periodismo, Facultad de Comunicación, Universidad de Sevilla, p. 54.

Araucaria. Revista Iberoamericana de Filosofia, Política, Humanidades y Relaciones Internacionales, año $23, \mathrm{n}^{\circ} 47$. Segundo cuatrimestre de 2021. Pp. 315-339. ISSN 1575-6823 e-ISSN 2340-2199 https://dx.doi.org/10.12795/araucaria.2021.i47.15 
Por último, no podemos olvidar la fuerza económica del control del presupuesto de la Generalitat por parte del Gobierno secesionista de Puigdemont, respecto de determinados medios de comunicación, especialmente públicos y el dinero destinado a los mismos. En el año 2017, los gastos asignados al Consejo Audiovisual de Cataluña ascendían a 5,3 millones de euros. La partida "533 referida a Medios de Comunicación Social" era de 309,5 millones de euros, de los que 289,9 millones estaban destinados a la Corporación Catalana de Medios Audiovisuales S.A. de la que, no lo olvidemos, dependen 6 canales de televisión, 4 emisoras de radio y una que emite por Internet, además de la Agencia Catalana de Noticias ${ }^{52}$.

\subsection{El Parlamento catalán: un órgano legítimo que actúa de manera ilegítima. De Poder constituido a Poder constituyente}

El nuevo Parlamento naciente de las elecciones autonómicas de septiembre de 2015, toma la decisión de sacar adelante el principal objetivo de su hoja de ruta: la independencia. Con ello, el Parlamento catalán pretende situar a una parte de España -Cataluña- al margen de la legalidad, de las normas de convivencia, de la paz social y de la seguridad jurídica. Quiere convertir a una Comunidad Autónoma donde rige el Estado de Derecho, en un territorio al margen de la ley, algo insólito en la Europa moderna y democrática.

En democracia todo se puede discutir, salvo lo básico. Lo básico en democracia no se discute, es tierra conquistada: principio de legalidad (art. 9.3 $\mathrm{CE}$ ), los derechos y las libertades (arts. 14 ss. CE), la separación de poderes, el respeto a los tribunales y sus resoluciones (art. $118 \mathrm{CE}$ ). La ley nos proporciona seguridad y garantiza la convivencia. No hay democracia sin respeto a la ley. La ley es la plasmación de la voluntad general, es la norma que nos permite convivir. La ley nos hace libres e iguales.

Podemos señalar el otoño de 2015 como el momento de inicio de la ruptura con el Estado de Derecho y democrático por parte del Parlamento catalán, que culminará el 27 de octubre de 2017. Se comienza a ver con claridad la enorme dificultad de convivir con quien discute lo básico y esencial: ¿cómo convivir con quien se sitúa por encima de leyes y tribunales?

El análisis que en otoño de 2015 se puede hacer del nuevo Parlamento catalán parece claro: tenemos un Parlamento legítimo como tal, fruto de su origen democrático, pero no de su actuación. Dicho con otras palabras, tiene legitimidad de origen, pero no de ejercicio, distinción importante cuyos orígenes se remontan a la Edad Media ${ }^{53}$. Lo que está haciendo el Parlamento

${ }^{52}$ Ver Rafael Calduch Cervera, "El fracaso internacional del independentismo catalán..., ob. cit., p. 144 y 145, nota $^{\circ} 25$.

${ }_{53}$ Sobre esta distinción ver Paloma Biglino Campos, "Crisis de la representación, legitimidad de ejercicio y formas de responsabilidad" en Revista de Derecho Politico, n 100, UNED, septiembre-diciembre 2017, p. 488 ss. 
de Cataluña es ilegítimo, aunque sea un Parlamento legítimo. La clave es no confundir el 'Qué' con el 'Quién'. El quién es legítimo, su qué o actividad no. Podemos dar otro paso en el análisis jurídico-constitucional. El nuevo Parlamento catalán, que es poder constituido fruto de la Constitución de 1978, pretende ser en su nuevo mandato poder constituyente. Evidentemente, no tiene ninguna legitimidad para tal transformación, que rompe todo el sistema político diseñado en nuestra Norma de convivencia de 1978. El Parlamento de Cataluña olvida que su razón de ser, existencia y legitimidad viene de la Constitución Española y del Estatuto catalán que la desarrolla, además de ser elegido democráticamente por el pueblo catalán. Fuera de ese ámbito, el Parlamento catalán no tiene legitimidad democrática, no puede hacer ni aprobar cualquier cosa que considere. En cierta medida, intenta interpretar la Constitución como se hacía en el siglo XIX, como un simple texto político y no como lo que es, un texto jurídico-político ${ }^{54}$. Pero incluso tampoco podría hacerlo el propio Parlamento español, que también es poder constituido, solo el poder soberano, esto es, el pueblo español, tiene la titularidad como poder constituyente: "el pueblo español, al aprobar la actual Constitución, no ha conferido esa facultad de opción a los Poderes Constituidos (Poder Ejecutivo y Poder Legislativo, fundamentalmente), sino que se la ha reservado él mismo, en tanto que titular del Poder Constituyente" 55 .

\subsection{Soledad internacional del Procés y la particular "ceguera" frente al No de la Unión Europea}

En otoño de 2015 la situación de Cataluña y su reto secesionista tuvo una cierta repercusión internacional, que es interesante apuntar, pues es unánime el rechazo al procés. El Secretario General de Naciones Unidas, Ban Ki-moon, se pronuncia al respecto con claridad: "Cataluña no está entre los territorios con derecho a la autodeterminación" 56 . En una línea similar se pronunciaron otros líderes mundiales como el Presidente Obama, Angela Merkel o David Cameron, que se decantan por una España fuerte y unida ${ }^{57}$. Dos años más tarde, el Presidente de Francia, Emmanuel Macron, mantenía la misma posición al manifestar al respecto que "solo conozco un socio y un amigo, que es España"58.

\footnotetext{
${ }^{54}$ Para evitar esas peligrosas tentaciones reduccionistas, Eduardo García de Enterría en 1980 publicó su conocida obra, La constitución como norma y el tribunal constitucional, Madrid, Civitas, $4^{\mathrm{a}}$ ed., 2006.

55 Ver Vicente Álvarez García, "La respuesta jurídica frente...", ob. cit., p. 20.

56 Ver El País, 30 de octubre de 2015 https://elpais.com/internacional/2015/10/30/ actualidad/1446231111 709046.html

57 Ver editorial de El País de 17 de septiembre de 2015 titulada "Mas, aislado": https://elpais. com/elpais/2015/09/16/opinion/1442428520 250027.html

58 Ver El Periódico de 16 de junio de 2017: https://www.elperiodico.com/es/ internacional/20170616/macron-cataluna-conozco-socio-amigo-6109948
}

Araucaria. Revista Iberoamericana de Filosofí, Política, Humanidades y Relaciones Internacionales, año $23, \mathrm{n}^{\circ} 47$. Segundo cuatrimestre de 2021. Pp. 315-339. ISSN 1575-6823 e-ISSN 2340-2199 https://dx.doi.org/10.12795/araucaria.2021.i47.15 
A nivel internacional podemos concluir, como sostiene Calduch Cervera, que la "nueva República de Cataluña no ha sido reconocida por ningún Estado o institución internacional. Más aún, los intentos de alcanzar un amparo jurídico a su reivindicación secesionista por el Comité de Derechos Humanos de Naciones Unidas o la Corte Europea de Derechos Humanos no han logrado, hasta el momento, ninguna respuesta favorable a sus reclamaciones" ${ }^{\prime 59}$.

Pero quizás fue la propia Unión Europea, a través del Presidente de la Comisión, Jean-Claude Juncker, la institución más rotunda al respecto: "Una Cataluña independiente estaría fuera de la UE" ${ }^{" 60}$. Sería pues como un tercer país, al que lógicamente no se le aplicarían los Tratados de la Unión.

Realmente la cuestión de la salida de la Unión Europa de una Cataluña independiente, merece una consideración más sosegada para entender la cercanía o lejanía del movimiento independentista con la realidad ${ }^{61}$. En febrero de 2013, por Decreto 113/2013, de 12 de febrero ${ }^{62}$, el Gobierno de la Generalitat crea el Consejo Asesor para la Transición Nacional $(\mathrm{CATN})^{63}$. El cual, entre otras competencias, asumiría el diseño de la actuación internacional y repercusión en el extranjero de la cuestión catalana, además de buscar apoyos a la misma. De los diferentes informes que elabora este Consejo, nos interesa el Informe $\mathbf{n}^{\mathbf{0}}$ 6: Las vías de integración de Cataluña en la UE, publicado en julio de 2014.

Resulta ciertamente extraño que en dicho informe aparezcan expresamente contempladas las negativas declaradas ${ }^{64}$ por los Presidentes de la Comisión Europea, Romano Prodi y posteriormente Durão Barroso ${ }^{65}$, también la del Presidente del Consejo Europeo, Van Rompuy: "Un Estado nuevo independiente sería un tercer país respecto de la UE y los tratados, desde el mismo día de su independencia, no se aplicarían en ese territorio"66. Sin embargo, el Informe

\footnotetext{
${ }^{59}$ Ver Rafael Calduch Cervera, "El fracaso internacional del independentismo catalán...,ob. cit., p. 131.

${ }^{60}$ Ver El País de 18 de septiembre de 2015 https:/elpais.com/politica/2015/09/17/ actualidad/1442481238 663863.html

${ }^{61}$ Ver Paola Lo Cascio, "IN OR OUT? Las políticas de internacionalización del Procés catalán y la producción de discurso en torno a la independencia (2012-2016)" en Steven Forti, Arnau González i Vilalta y Enric Ucelay-DA Cal (eds.), El Proceso separatista en Cataluña... ob. cit., pp. 131-149.

62 Ver Diario Oficial de la Generalidad de Cataluña no 6315 de 14 de febrero de 2013.

${ }^{63}$ Sobre el mismo, ver Josu de Miguel Bárcena, "Manual para construir un estado. Los informes del Consejo Asesor para la Transición Nacional de Cataluña, en Teoría y realidad constitucional, $\mathrm{n}^{\circ}$ 37, ob. cit., pp. 499-527.

${ }^{64}$ Expresamente en diciembre de 2013, ver La Vanguardia de 3 de diciembre y El Mundo de 13 de diciembre.

${ }^{65}$ Ver p. 11 del ctdo. Informe $\mathrm{n}^{\circ} 6$.

${ }^{66}$ Ctdo. en Paola Lo Cascio, "IN OR OUT? Las políticas...”, ob. cit., p. 144, nota a píe no 34.

El número de autoridades de la UE que en estos años se manifestaron en el sentido apuntado de una Cataluña independiente fuera de la UE no es menor, así lo hicieron también el portavoz del Parlamento Europeo Jaume Duch en Cataluña Radio; Michael Barnier, Comisario de Mercado Interior y Servicios Financieros; la también Comisaria de Justicia y Derechos Fundamentales, Viviane Reding; Joaquín Almunia, exvicepresidente de la UE y Pia Ahrenkilde, portavoz de la Comisión Europea, ver Fernando Carrera, Fernando Roca y Pedro Pérez-Cuesta, Las mentiras del independentismo catalán, ob. cit., p. 43 y 44.
} 
del CATN sostiene sorprendentemente la posibilidad de, al ser un supuesto único en la historia de la UE, ésta adopte "una actitud flexible [...] buscando en cada caso la solución ad hoc que mejor ha ido para combinar los intereses de la UE -incluida su voluntad integradora fundacional- y los intereses de sus Estados miembros con los intereses y las características específicas de los países candidatos"67. Incluso en el programa electoral que Junts pel sí presentó en las elecciones del 27 de septiembre de 2015 se afirmaba que "la pertenencia a la Unión y al Euro es fundamental para garantizar la continuidad y la mejora de la prosperidad conseguida. No se puede poner en riesgo esta pertenencia. Por otro lado, contrariamente a lo que algunos quieren hacer creer, esta permanencia no está amenazada por la independencia"68.

No es bueno confundir los deseos con la realidad. El independentismo en este punto, como en muchos otros, se encontraba fuera de la misma, por más que ésta se hubiera manifestado en varias ocasiones, como hemos apuntado. La soledad del procés en la Unión Europea fue total: "los independentistas no imaginaron que la Unión Europea fuera a dar un respaldo unánime al Estado español"69.

No le falta razón a López Garrido cuanto afirma, con realismo jurídico, que "si una Cataluña supuestamente independiente quisiera ser parte de la Unión -como la Generalitat afirma- tendría que seguir el trámite del artículo 49 TUE. Debería solicitar el ingreso y esperar que los actuales Estados miembros de la Unión -todos- aceptasen iniciar el procedimiento, continuar su trámite completo y votar -también por unanimidad- la aceptación final de Cataluña como parte de los Tratados de la Unión Europea"70.

Por lo demás, no solo estaría fuera de la Unión Europea una Cataluña independiente, también quedaría fuera de otras "instituciones internacionales como las Naciones Unidas, el Fondo Monetario Internacional, la Organización Tratado Atlántico Norte" "71. En fin, como sostiene con realismo y claridad Cortina de la Concha en una línea muy similar a la apuntada: "como ha quedado patente, modificar las fronteras de la Unión Europea, exigir un puesto en la Alianza Atlántica, lograr la legitimidad de Naciones Unidas o hacerse un hueco en la mesa del Mediterráneo es imposible"72.

${ }^{67}$ Ver Paola Lo Cascio, "IN OR OUT? Las políticas...", ob. cit., 13.

${ }^{68}$ Ctdo. en Fernando Carrera, Fernando Roca y Pedro Pérez-Cuesta, Las mentiras del independentismo catalán, ob. cit., p. 35.

${ }^{69}$ Ignacio Sánchez-Cuenca, ob. cit., p. 195

${ }^{70}$ Ver Diego López Garrido (coord.) Cataluña ante la Unión Europea. Consecuencias jurídicas de la independencia, Fundación Alternativas, septiembre, 2015, p. 12:

https://www.fundacionalternativas.org/public/storage/fundacion_documentos_archivos/ c4bf6ae25f99cbb0f6209c3ed715d972.pdf

${ }^{71}$ Ver Fernando Carrera, Fernando Roca y Pedro Pérez-Cuesta, Las mentiras del independentismo catalán, ob. cit., p. 33.

${ }^{72}$ Ver Gabriel Cortina de la Concha, "El desafío independentista catalán", en IV Congreso ADESyD (Asociación de Diplomados Españoles en Seguridad y Defensa) Compartiendo (visiones

Araucaria. Revista Iberoamericana de Filosofí, Política, Humanidades y Relaciones Internacionales, año $23, \mathrm{n}^{\circ} 47$. Segundo cuatrimestre de 2021. Pp. 315-339. ISSN 1575-6823 e-ISSN 2340-2199 https://dx.doi.org/10.12795/araucaria.2021.i47.15 


\section{Año 2016: transición para preparar la declaración unilateral de independencia. EI Presidente Puigdemont}

A efectos de hechos relevantes, se puede considerar el año 2016 como un año de transición y de preparación para la declaración unilateral de independencia de octubre de 2017. Lo más destacable de este año es el nombramiento de Carles Puigdemont como Presidente de la Generalidad de Cataluña el 10 de enero de 2016. Le apoyan 70 de los 135 diputados del Parlamento catalán, previamente Artur Mas había renunciado a ser investido, según explicó, para facilitar la constitución de un nuevo gobierno de independencia.

\section{Año 2017: el año decisivo, ruptura del sistema democrático}

En este apartado apuntaremos los hitos más relevantes que se producen en este aciago año 2017 para la democracia en Cataluña y en España ${ }^{73}$. El 9 de junio de 2017, el Presidente Puigdemont anuncia el referéndum de autodeterminación para el día 1 de octubre de 2017. La pregunta que se hará al pueblo catalán es la siguiente: “¿quiere que Cataluña sea un Estado independiente en forma de república?”.

A finales del mes de julio el Parlamento de Cataluña da otro paso más hacia la ilegitimidad en su actuar representativo e institucional con la última modificación de su Reglamento para tramitar sin debate, sin enmiendas y en un solo día las denominadas «leyes de desconexión». Como ya hemos señalado, nadie duda de la legitimidad del Parlamento catalán fruto de unas elecciones autonómicas en el marco de la Constitución Española y del Estatuto de Autonomía; sin embargo, no todo lo que hace un parlamento elegido legítimamente es legítimo. Esta es la auténtica cuestión de fondo que se desarrolla en diferentes episodios, la reforma del artículo 135.2 del Reglamento del Parlamento, es el último de ellos $^{74}$, obligando una vez más a pronunciarse al Tribunal Constitucional (STC 139/2017, de 29 de noviembre). No le falta razón a Pérez de los Cobos Hernández al destacar el "menosprecio hacia el Derecho en que ha terminado derivando el proceso independentista [...]. El uso fraudulento del ordenamiento jurídico, en aras de alcanzar los objetivos políticos a cualquier precio, no hace sino envilecer cualquier propósito" 75 .

\footnotetext{
de) Seguridad, vol. IV, mayo de 2018, p. 41.

${ }^{73}$ Más extensamente, ver Elisa Pérez de los Cobos Hernández, "Desafío del independentismo catalán al Estado Autonómico" en Revista Aragonesa de Administración Pública, n 55, 2020, pp. $278-361$.

${ }^{74}$ Ver Daniel Fernández Cañueto, "Las consecuencias de la reforma del art. 135.2 del Reglamento del Parlamento de Cataluña para aprobar la Ley de referéndum y la de transitoriedad jurídica: suspensión y STC 139/2017”, en Revista Vasca de Administración Pública n 111, mayo-agosto 2018, pp. 207-246: https://aelpa.org/web-2018/wp-content/uploads/2018/12/RVAP-Daniel-Fernandez.pdf

${ }^{75}$ Ver Elisa Pérez de los Cobos Hernández: "Desafío del independentismo..., ob. cit., p. 358-359.
} 
El 6 de septiembre el Parlamento catalán aprueba una ley de referéndum para dotar de legalidad al referéndum del 1 de octubre, la Ley 19/2017: "la aprobación de esta norma supuso una quiebra explícita de la legalidad española y el sistema constitucional"'76. Así, y como desarrollo de esta Ley, se aprueban dos Decretos del Gobierno de Cataluña, el Decreto 139/2017, de 6 de septiembre, de convocatoria del referéndum de autodeterminación de Cataluña y el Decreto 140/2017, de 7 de septiembre, de normas complementarias para la realización del citado referéndum. Al día siguiente, el Parlamento catalán aprueba la Ley 20/2017, de transitoriedad jurídica y fundacional de la República. Las cuatro normas jurídicas son recurridas por el Gobierno de España ante el Tribunal Constitucional, que suspende su aplicación.

Los días 20 y 21 de septiembre unos 5.000 ciudadanos independentistas impiden a una comisión judicial su entrada y registro a varios edificios, entre ellos la Consellería de Economía. Se produjeron importantes alteraciones del orden público, "impidiendo a la comisión judicial abandonarlos, enfrentándose a los agentes de la autoridad, dañando vehículos policiales e incluso sustrayendo las armas que se encontraban en su interior" 77.

Al final, el día 1 de octubre se produce el referéndum sin las mínimas garantías democráticas sobre su rigor y seriedad. La participación es del $43 \%$, menor participación que la de la aprobación del Estatuto de autonomía de 2006 que tuvo el 48,85\%. El $90 \%$ de los votos son a favor del sí, algo más de 2 millones de votos.

Muestra de la soledad internacional del procés, especialmente en el seno de la Unión Europea, como ya hemos estudiado, es la declaración de la Comisión Europea del día 2 de octubre, justo un día después, calificando expresamente de ilegal el referéndum realizado en Cataluña: "Under the Spanish Constitution, yesterday's vote in Catalonia was not legal. For the European Commission, as President Juncker has reiterated repeatedly, this is an internal matter for Spain that has to be dealt with in line with the constitutional order of Spain. We also reiterate the legal position held by this Commission as well as by its predecessors. If a referendum were to be organised in line with the Spanish Constitution it would mean that the territory leaving would find itself outside of the European Union. Beyond the purely legal aspects of this matter, the Commission believes that these are times for unity and stability, not divisiveness and fragmentation"78.

El 3 de octubre, el Rey Felipe VI se dirige a la Nación en un mensaje televisado que todo lo cambia, tanto a nivel interno como a nivel internacional,

En una línea parecida, Antoni Bayona, No todo vale. La mirada de un jurista a las entrañas del procés, Barcelona, Península, 2019.

76 Ver Miguel Ángel Cano Paños, "Los delitos de rebelión y sedición..., ob. cit., p. 4.

77 Ibidem, p. 5.

78 Ver: https://ec.europa.eu/commission/presscorner/detail/en/STATEMENT $17 \quad 3626$

Araucaria. Revista Iberoamericana de Filosofia, Política, Humanidades y Relaciones Internacionales, año $23, \mathrm{n}^{\circ} 47$. Segundo cuatrimestre de 2021. Pp. 315-339. ISSN 1575-6823 e-ISSN 2340-2199 https://dx.doi.org/10.12795/araucaria.2021.i47.15 
quedando claro que el procés ha fracasado y no va ninguna parte, como por lo demás, todo el mundo sabía. Felipe VI, como Jefe del Estado, ejerce lógicamente sus funciones reguladas en el artículo 56.1 de la Constitución: "arbitra y modera el funcionamiento regular de las instituciones".

El 10 de octubre los partidos independentistas firman una declaración de independencia en el Parlamento de Cataluña. Acto seguido el Presidente Puigdemont la deja en suspenso temporalmente, según señala, para permitir una mediación internacional y una solución negociada.

El día 27 de octubre Junts pel Sí y la CUP presentan una resolución al Parlamento para que el Gobierno de la Generalidad aplique la independencia suspendida algunos días antes por el Presidente Puigdemont. La votación se aprueba con 70 votos a favor, 10 en contra y 2 abstenciones. No participan en la misma, habiendo salido de la Cámara previamente, los grupos parlamentarios de ciudadanos, socialista y popular. Se declara la independencia. El Presidente Rajoy, con la mayoría absoluta del Senado, aplica la Constitución española, concretamente su artículo 155. La vicepresidenta Soraya Sainz de Santamaría asume la presidencia de Cataluña. Entre finales de noviembre y primeros de diciembre, parte del gobierno de Cataluña huye de España y otra parte son encarcelados.

Parece bastante claro que "el independentismo calculó mal sus fuerzas [...] no supo parar a tiempo. [...]. Las decisiones que tomó el independentismo a partir de ahí (1 de octubre de 2017) parecen encarnar una especie de suspensión del principio de realidad"79. O lo que es aún peor, sabían perfectamente de la imposibilidad de la independencia. Así lo entiende Cano Paños "los líderes del procés lograron seducir, engañar y utilizar en su propio beneficio a una parte de la ciudadanía catalana, la cual creyó en su imaginario colectivo que la ruptura con el Estado español y la creación de un nuevo país era algo factible, cuando sus líderes sabían de antemano que eso era algo literalmente imposible de alcanzar"\$0.

Han ido incluso más allá que el caso de Quebec y la conocida Sentencia, tan citada por el nacionalismo catalán, de la Corte Suprema de Canadá de 20 de agosto de 1998 que "rechazó la secesión unilateral y sólo admitió un proceso de independencia negociada siempre y cuando hubiese alcanzado 'a clear referéndum result" "'81.

El 21 de diciembre de 2017 se celebran elecciones en Cataluña. Ciudadanos es el partido más votado, pero la mayoría absoluta es de los partidos rupturistas. El 10 de mayo de 2018 Quim Torra (Junts per Catalunya) es nombrado presidente de la Generalidad por el Parlamento catalán.

\footnotetext{
${ }^{79}$ Ignacio Sánchez-Cuenca, ob. cit., p. 196.

${ }^{80}$ Ver Miguel Ángel Cano Paños, "Los delitos de rebelión y sedición..., ob. cit., p. 37.

${ }^{81}$ Ver Rafael Calduch Cervera, "El fracaso internacional del independentismo catalán..., ob. cit., p. 142 .
}

Araucaria. Revista Iberoamericana de Filosofia, Politica, Humanidades y Relaciones Internacionales, año $23, \mathrm{n}^{\circ} 47$. Segundo cuatrimestre de 2021. Pp. 315-339. ISSN 1575-6823 e-ISSN 2340-2199 https://dx.doi.org/10.12795/araucaria.2021.i47.15 


\section{Conclusiones}

Exponemos a continuación las siguientes conclusiones que estimo han quedado suficientemente demostradas en este trabajo:

PRIMERA. Ausencia de contacto con la realidad. Sin duda este es el gran problema del nacionalismo catalán: está fuera de la realidad. Por ello, su fracaso es inevitable. Ahí están los datos expuestos en los cuatro campos estudiados: 1) Soledad internacional total, con incidencia especial en el ámbito de la Unión Europea; 2) Inviabilidad económica de una Cataluña independiente; 3) Ruptura del marco jurídico, no se respetan ni las leyes, ni los tribunales; y 4) Alta conflictividad social y merma de la calidad democrática, pilotada por un Parlamento ilegítimo en su actuar. Por lo demás, y es lo más trágico de este proyecto rupturista, todas las partes pierden con él: a) los no nacionalistas evidentemente por no compartirlo y tener que sufrirlo; y b) los nacionalistas por su carácter inviable.

SEGUNDA. La falacia demostrada del inexistente derecho a decidir, pilar argumental del bloque rupturista. Hemos visto que no existe este derecho y el que sí existe, el derecho de autodeterminación, no es aplicable. Por último, el derecho de secesión, que también existe, solo lo reconocen en el mundo cinco países: Etiopía, Liechtenstein, San Cristóbal y Nieves ${ }^{82}$, Sudán y Uzbekistán.

TERCERA. A nivel mediático han quedado demostrados cuatro puntos: a) la mayor presencia del bloque nacionalismo catalán frente al bloque democrático-constitucionalista, especialmente en YouTube, Instagram, Twitter, incluso en agencias internacionales; b) el recurso a las fake news por parte del bloque independentista; c) la injerencia rusa en Cataluña a través de RT o Sputnik; d) el destino de 289,9 millones de euros de la Generalidad presidida por Puigdemont a la Corporación Catalana de Medios Audiovisuales S.A. en el año 2017.

CUARTA. El gobierno y el parlamento catalana controlados por el nacionalismo rupturista en el trienio estudiado (2015-2017), han demostrado con su actuar su indudable carácter antisistema, respecto del sistema democrático español fruto de la Constitución de 1978. Así, no han respetado leyes, no han respetado tribunales y han transformado el parlamento catalán de poder constituido en poder constituyente. Todo ello, difícil es negarlo, constituye una verdadera aberración democrática.

\footnotetext{
${ }^{82}$ País caribeño en el norte antillano.
} 
Tenemos que comenzar a expresar con claridad que el nacionalismo es un pensamiento en nada constructivo, que no genera espacios de libertad y convivencia, tendiendo a sociedades cerradas y excluyentes donde el diferente a nivel ideológico, no es bienvenido. La democracia, el pluralismo y la tolerancia tienen bastantes dificultades en los regímenes nacionalistas, que se suelen retroalimentar. Tiene razón Ignacio Sánchez-Cuenca cuando afirma que "el resurgir del nacionalismo español ha endurecido mucho el discurso. $\mathrm{Y}$ ha encontrado un infatigable aliado en el nacionalismo catalán. Juntos han llevado la descalificación mutua a niveles inaceptables" ${ }^{\prime 3}$. Es lo que tiene el nacionalismo.

Mario Bunge, profesor emérito de filosofía de la Universidad McGill de Canadá, describe en un ilustrativo párrafo su experiencia de más de medio siglo viviendo en Quebec y la actuación del gobierno independentista. Nos va a resultar bastante familiar con la situación de Cataluña, pero mejor que juzgue el lector. En referencia a las acciones de dicho gobierno, apunta las siguientes: "reducir los derechos de los quebequeses de habla inglesa y de los alófonos. Se prohibieron los letreros comerciales en lenguas distintas al québécois, el ingreso de niños de familias sin raíces británicas en las escuelas de lengua inglesa y el acceso a los no quebequeses en las burocracias provincial y municipal. A esas medidas se agregó la súbita agresividad de los independentistas para quienes no compartían su ideal. La mayoría de la población sintió miedo por primera vez en la historia de la provincia. Las grandes compañías trasladaron sus oficinas a los EE UU o a Toronto, que pasó a ocupar el primer lugar en la economía canadiense. Nadie invirtió en empresas provinciales, y los jóvenes educados en escuelas y universidades de lengua inglesa, como McGill, donde enseñábamos mi mujer y yo, se iban de la provincia en cuanto se graduaban. En suma, la provincia de Quebec se empobreció económica y culturalmente durante los gobiernos separatistas" $"$.

\section{Referencias bibliográficas}

Álvarez García Vicente, "La respuesta jurídica frente al desafío independentista catalán" en Anuario de la Facultad de Derecho de la UEx, n 33, 2017, pp. 1-46.

Bayona Antoni, No todo vale. La mirada de un jurista a las entrañas del procés, Barcelona, Península, 2019.

Biglino Campos Paloma, "Crisis de la representación, legitimidad de ejercicio y formas de responsabilidad" en Revista de Derecho Político, n 100, UNED, septiembrediciembre 2017, pp. 481-511.

\footnotetext{
${ }^{83}$ Ignacio Sánchez-Cuenca, ob. cit., p. 12.

${ }^{84}$ Mario Bunge, prólogo “¿cuándo se justifica una lucha por la independencia?” en Paco Moreno, El seny perdido. El independentismo catalán no tiene razón, Pamplona, ed. Laetoli, 2016, pp. 7 y 8.
} 
Borell Josep y Llorach Joan, Las cuentas y los cuentos de la independencia, Madrid, ed. Los libros de la catarata, 2015.

Bunge Mario, “cuándo se justifica una lucha por la independencia?” en Paco Moreno, El seny perdido. El independentismo catalán no tiene razón, Prólogo, Pamplona, ed. Laetoli, 2016.

Calduch Cervera Rafael, "El fracaso internacional del independentismo catalán: causas jurídicas y políticas" en Anuario Español de Derecho Internacional, 2019, vol. 35, pp. 127-148.

Cano Paños Miguel Ángel, “Los delitos de rebelión y sedición en el ordenamiento jurídico español y su eventual aplicación al proceso independentista catalán" en Revista electrónica de Estudios Penales y de la Seguridad, nº 5, 2019, pp. 1-44.

Carrasco Polaino Rafael, Villar Cirujano Ernesto y Tejedor Fuentes Laura, "Twitter como herramienta de comunicación política en el contexto del referéndum independentista catalán: asociaciones ciudadanas frente a instituciones públicas" en Icono 14, enerojunio 2018, vol. 16, $\mathrm{n}^{\mathrm{o}}$ 1, pp. 64-85.

Carrera Fernando, Roca Fernando y Pérez-Cuesta Pedro, Las mentiras del independentismo catalán, Madrid, ed. BuenasLetras, 2017.

Cartes Barroso Manuel Jesús, "El uso de Instagram por los partidos políticos catalanes durante el referéndum del 1 - 0" en Revista de Comunicación de la SEECI, n 47, 15 noviembre 2018-15 marzo 2019, pp. 17-36.

Cortina de la Concha Gabriel, "El desafío independentista catalán”, en IV Congreso ADESyD (Asociación de Diplomados Españoles en Seguridad y Defensa) Compartiendo (visiones de) Seguridad, vol. IV, mayo de 2018, pp. 31-45.

Cruz Villalón Pedro, "La protección extraordinaria del Estado" en Predieri y García de Enterría (Dirs.), La Constitución Española de 1978, Madrid, Civitas, 1980.

Delgado Balongo Almudena, "El fenómeno de la desinformación en twitter: las fake news del 1-O sobre el conflicto catalán", TFG dirigido por la doctora Irene Tenorio Vázquez, 2018-2019, grado de periodismo, Facultad de Comunicación, Universidad de Sevilla.

Dowling Andrew, "La calle como plataforma de comunicación. De la Crida a la Assemblea Nacional Catalana" en Forti Steven, González i Vilalta Arnau y Ucelay-Da Cal Enric, El Proceso separatista en Cataluña. Análisis de un pasado reciente (2006-2017), Granada, Comares, 2017.

Fernández Cañueto Daniel, "Las consecuencias de la reforma del art. 135.2 del Reglamento del Parlamento de Cataluña para aprobar la Ley de referéndum y la de transitoriedad jurídica: suspensión y STC 139/2017”, en Revista Vasca de Administración Pública $\mathrm{n}^{\mathrm{o}} 111$, mayo-agosto 2018, pp. 207-246.

Fernández de Casadevante Mayordomo Pablo "La secesión vía reforma constitucional en el derecho comparado" en Carlos Fernández de Casadevante Romani (dtor.), Consecuencias jurídicas de la secesión de entidades territoriales. Una visión para España, Cizur Menor, Aranzadi, 2020, pp. 67-100.

Fernández de Casadevante Carlos, "El proyecto independentista catalán a la luz del Derecho Internacional y de la Unión Europea" en Cataluña en claro, ed. FAES, 2014, pp. 83-98.

Fernández-Llebrez González Fernando, "Mecanismos ambientales, cognitivos y relacionales en el surgimiento del actual movimiento independentista catalán", en Revista de Estudios Regionales, nº 117, 2020, pp. 97-122. 
Forti Steven, González i Vilalta Arnau y Ucelay-Da Cal Enric, El Proceso separatista en Cataluña. Análisis de un pasado reciente (2006-2017), Granada, Comares, 2017.

García de Enterría Eduardo, Estudios sobre autonomías territoriales, Madrid, Civitas, 1985.

García de Enterría Eduardo, La constitución como norma y el tribunal constitucional, Madrid, Civitas, $4^{\mathrm{a}}$ ed., 2006.

García Varela Concha, "Putin en Cataluña. La cobertura del diario El País sobre la injerencia rusa en el conflicto catalán (del 1 de octubre hasta el 21 de diciembre de 2017)", TFG dirigido por Juan Carlos Fernández Serrato, 2018-2019, grado de periodismo, Facultad de Comunicación, Universidad de Sevilla.

García-Pelayo Manuel, Derecho constitucional comparado, Madrid, Alianza, 1999.

Gil Ramírez Marta, "El uso de YouTube en el Procés catalán. Comunicación política a través de los social media: ¿prosumidores mediatiados?" en Estudios sobre el mensaje periodístico, ediciones complutense, $\mathrm{n}^{\circ} 25$ (1) 2019, pp. 213-234.

Gil-Robles Gil-Delgado José María en Óscar Alzaga Villaamil (Dir.), Comentarios a la Constitución Española de 1978, Madrid, Cortes Generales/EDERSA, 1999, tomo XI, pp. 501-520.

Leal José Luis, El coste de la independencia, el País de los Negocios 5 de noviembre de 2017: https://elpais.com/economia/2017/11/02/actualidad/1509638840 783543.html

Lo Cascio Paola, "IN OR OUT? Las políticas de internacionalización del Procés catalán y la producción de discurso en torno a la independencia (2012-2016)" en Forti Steven, González i Vilalta Arnau y Ucelay-Da Cal Enric, El Proceso separatista en Cataluña. Análisis de un pasado reciente (2006-2017), Granada, Comares, 2017, pp. 131-149.

López Garrido Diego (coord.) Cataluña ante la Unión Europea. Consecuencias jurídicas de la independencia, Fundación Alternativas, septiembre, 2015, pp. 1-21.

López-Olano Carlos y Fenoll Vicente, "La polarización mediática en el proceso de independencia en Cataluña. Estudio comparativo del tratamiento en RT" en Revista Mediterránea de Comunicación, $\mathrm{n}^{\circ} 11$ (1), 2020, pp. 261-272.

Miguel Bárcena Josu de, "Manual para construir un estado. Los informes del Consejo Asesor para la Transición Nacional de Cataluña", en Teoría y realidad constitucional, $\mathrm{n}^{\circ} 37.1^{\circ}$ semestre 2016, monográfico "La cuestión catalana", pp. 499-527.

Pérez de los Cobos Hernández Elisa, "Desafío del independentismo catalán al Estado Autonómico" en Revista Aragonesa de Administración Pública, n 55, 2020, pp. 278-361.

Pirenne Jacques, Historia Universal. Las grandes corrientes de la historia, vol. I, Barcelona, ediciones LEO, 1953.

Pons Rafols Xavier, Cataluña: Derecho a decidir y derecho internacional, Reus, Madrid, 2015.

Prieto Navarro Evaristo, Jürgen Habermas, acción comunicativa e identidad politica, Madrid, Centro de Estudios Políticos y Constitucionales, 2003.

Rodríguez Mesa Cristina, "Discurso y prácticas políticas del catalanismo: Del nacionalismo al independentismo instrumental" en Forti Steven, González i Vilalta Arnau y Ucelay-Da Cal Enric, El Proceso separatista en Cataluña. Análisis de un pasado reciente (2006-2017), Granada, Comares, 2017.

Sagarra Trías Eduard (coord.), ¿Existe el derecho a decidir? Preguntas y respuestas sobre el proceso abierto en Cataluña, Tibidabo, Barcelona, 2014. 
Sánchez-Cuenca Ignacio, La confusión nacional. La democracia española ante la crisis catalana, Madrid, Catarata, 2018.

Teoría y Realidad Constitucional, $\mathrm{n}^{\circ} 37.1^{\circ}$ semestre 2016, monográfico "La cuestión catalana", encuesta, pp. 13-98.

Vargas Llosa, Mario, entrevista en $A B C$ de 17 de enero de 2021, pp. 12-14: https://www.abc. es/cultura/abci-entrevista-vargas-llosa-ley-celaa-disparate-absoluto-202101170059 video.html

Vergottini Giuseppe de, "Referéndum y secesión" en Teoría y realidad constitucional, $\mathrm{n}^{\circ}$ 43, 2019, pp. 103-119.

VV.AA., El derecho a decidir. Teoría y práctica de un nuevo derecho, Atelier, Barcelona, 2015 . 
